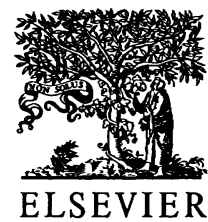

Journal of Vocational Rehabilitation 10 (1998) 183

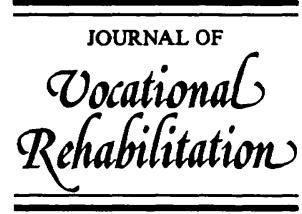

\title{
Announcement
}

\section{Marketing, Managing, and Merchandising in the BEP}

\author{
Dallas, TX \\ March 29-April 1, 1998 \\ Keynote Speaker: Mr. Barry Ford, Southwest Airlines \\ Sponsor: RRTC on Blindness \& Low Vision \\ Contact: John Maxson \\ Tel.: +1 $601325-2001$
}

Goal: Identify and implement specific strategies for meeting multiple BEP market demands in an ever-changing business environment. 